\title{
A LOW-COST FEMTOSATELLITE TO ENABLE DISTRIBUTED SPACE MISSIONS
}

\author{
Author \\ Major David J. Barnhart, USAF, dave_barnhart@msn.com \\ Surrey Space Centre, University of Surrey, United Kingdom \\ Co-Authors \\ Dr. Tanya Vladimirova, t.vladimirova@surrey.ac.uk \\ Surrey Space Centre, University of Surrey, United Kingdom \\ Dr. Adam M. Baker, a.baker@sstl.co.uk \\ Prof. Sir Martin N. Sweeting, m.sweeting@sstl.co.uk \\ Surrey Satellite Technology Limited, United Kingdom
}

\begin{abstract}
A new class of distributed space missions is emerging which requires hundreds to thousands of satellites for real-time, distributed, multi-point sensing to accomplish long-awaited remote sensing and science objectives. These missions, stymied by the lack of a lowcost mass-producible solution, can become reality by merging the concepts of distributed satellite systems and terrestrial wireless sensor networks. However, unlike terrestrial sensor nodes, space-based nodes must survive unique environmental hazards while undergoing complex orbital dynamics. A novel sub-kilogram very small satellite design is needed to meet these requirements. Subkilogram satellite concepts are developing elsewhere, such as traditional picosatellites and microengineered aerospace systems. Although viable technical solutions, these technologies currently come at a high cost due to their reliance on high-density technology or custom manufacturing processes. While evaluating these technologies, two untapped technology areas became evident that uniquely encompass low cost and mass producibility by leveraging existing commercial production techniques: satellite-on-a-chip (SpaceChip) and satellite-on-a printed-circuit-board (PCBSat). This paper focuses on the design, build, and test results of a prototype PCBSat with a prototype unit cost less than \$300. The paper concludes with mission applications and future direction.
\end{abstract}

\section{INTRODUCTION}

A new class of distributed space missions (DSMs) is emerging which requires hundreds to thousands of satellites for realtime, distributed, multi-point sensing to accomplish longawaited remote sensing and science objectives. These missions, stymied by the lack of a low-cost mass-producible solution, can become reality by merging the concepts of distributed satellite systems (DSSs) and terrestrial wireless sensor networks (WSNs) [1]. However, unlike terrestrial sensor nodes, space-based nodes must survive unique environmental hazards while undergoing complex orbital dynamics. We believe that a novel very small satellite (VSS) design can fulfill these requirements. In this paper, we define a VSS as having a mass less than one kilogram.

Sub-kilogram satellite concepts, such as traditional picosatellites and microengineered aerospace systems have been around for some time. Although viable technical solutions, they come at a high cost due to labor-intensive or custom manufacturing processes. While evaluating the potential design space, two untapped technology areas were discovered that uniquely encompass low cost and mass producibility by leveraging existing commercial production techniques: satellite-on-a-chip and satellite-on-a-printed circuit board (satellite-on-a-PCB). The initial results of SpaceChip, which is a monolithic "satellite-on-a-chip" based on commercial CMOS technology, was first presented in [2] and updated in [3].

This paper focuses on the design, build, and test results of a prototype satellite-on-a-PCB. It is presented in a problemsolution format where the "problem" is the emerging set
DSMs where real-time, distributed, multi-point sensing is required to accomplish long-awaited remote sensing and science objectives. The solution space of low-cost massproducible VSS technologies is then discussed where a promising solution of satellite-on-a-PCB was discovered. The design, build, and test results of the prototype are presented. Mission applications, challenges, and future direction of the work are then discussed.

\section{DISTRIBUTED SPACE MISSIONS}

The interchangeable terms, distributed satellite system and distributed space system, evoke the promise of realizing missions that have not been previously possible, while the term constellation is associated with a simpler form of the DSS concept. Jilla defines a DSS simply as "a system of multiple satellites designed to work in a coordinated fashion to perform a mission" [4]. Burns considers a DSS to be "an endto-end system including two or more space vehicles and a cooperative infrastructure for science measurement, data acquisition, processing, analysis, and distribution" [5]. We find that Shaw offers the most complete definition in [6] identifying two formal types of DSSs. The first type relates to system implementations where multiple satellites are sparsely distributed as a traditional constellation in order to meet various mission requirements. Constellation scenarios do not typically require precise orientation between spacecraft but optionally may require propulsive stationkeeping. Satellites in the constellation are usually linked via ground relays and systems. More recently, crosslinks, sometimes referred to as inter-satellite links, have enabled higher interconnectivity and to a limited degree, autonomy.

This material is declared a work of the United States Government and is not subject to copyright protection in the United States. 1 
The second DSS type proposed by Shaw [6] introduces the concept of a local cluster, where satellites are intentionally placed close together in the same orbit to train on a common target. Optionally, this cluster of satellites may have a more complex instantiation, namely a formation. Formation flying requires that satellites in a cluster maintain precise spacing and orientation relative to each other, with the level of precision based on mission requirements. This directly implies that the spacecraft must have exact real-time location knowledge of all nodes and a propulsion system to maintain the formation. Formations cannot naturally exist in orbit very long before orbital perturbations disturb the arrangement. The motivation for formation flying is to synthesize an aperture, antenna, or some other sensor suite to achieve mission performance levels that cannot be currently reached by the largest single satellite. To date, most aspects of this concept have been widely studied, but the first implementation has yet to be realized, with the exception of a few initial experiments discussed later.

We divide DSSs into two classes - constellation and cluster, as shown in Figure 1; based on predominant characteristics and previous publications [4]-[6]. These two classes are not meant to be mutually exclusive. For example, a formation flying cluster inherently requires crosslinks. To the best of the author's knowledge, all of the DSSs to date have been constellations utilizing ground links, with the exception of IRIDIUM and MILSTAR as will be discussed. Popular terms, such as swarm, are often misused in the literature due to multiple meanings and uses. Due to the lack of consensus, this term is not part of the classification diagram in Figure 1.

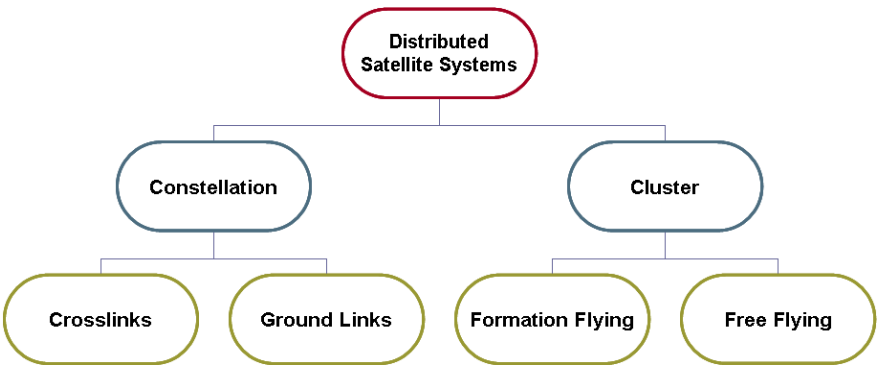

Figure 1. Distributed Satellite Systems

\subsection{Current Distributed Satellite Systems}

Here we present current DSSs grouped in the four typical mission categories: communications, navigation, remote sensing, and science, which includes space exploration.

Garrison summarizes the first, largest, and best example to date of a constellation utilizing crosslinks: the $\$ 5$ billion IRIDIUM global mobile phone communications system launched in 1997 [7]. IRIDIUM is a constellation of 66 satellites, each weighing $689 \mathrm{~kg}$, which provides global telecommunications services with very low latency to users with compact handsets. IRIDIUM is also one of the first DSSs with some degree of autonomy. Peters focuses on the fact that IRIDIUM is the only commercial system to date that employs RF crosslinks [8]. Although everyone realizes the phenomenal advantages of crosslinks, their high cost and complexity have discouraged any new systems from being fielded, with the exception of the U.S. military's \$10 billion MILSTAR system.
Users worldwide currently enjoy free use of the U.S. Air Force Global Positioning System (GPS) constellation. The constellation is composed of 24 satellites in semi-synchronous orbits, placed evenly in six planes designed to provide position and timing information to users on land, sea, air, and now space. The system costs $\$ 400$ million annually to operate and sustain. The Russians operate a similar system called GLONASS that utilizes 12 to 14 satellites in two planes. The European Union recently funded and launched the $\$ 36$ million, $660 \mathrm{~kg}$ GIOVE-A technology pathfinder mission to support the development of Galileo.

Commercial imagery applications, where satellites take visible and IR images of specific regions of interest in the world are also widespread. Commercial imagery is used for mapping, agricultural data, disaster monitoring, and other requirements. Systems such as QuickBird, OrbView, IKONOS, SPOT, and Landsat offer resolutions up to 0.6 meters and are all classified as medium to large satellites. None of these systems qualifies as a DSS, as they are all single-satellite systems. However, some recent consolidation in the industry has effectively created a new imaging constellation.

Small satellites have recently entered the Earth observation market. The Disaster Monitoring Constellation (DMC) developed by Surrey Satellite Technology Ltd. (SSTL) is composed of five $\$ 8$ million, $166 \mathrm{~kg}$ Earth-imaging satellites. DMC offers an unprecedented revisit time of 24 hours, versus days or weeks from other commercially available imaging systems [9]. DMC is considered the first Earth imaging constellation.

The European Space Agency (ESA) launched the \$315 million Cluster mission in 2000. The mission of Cluster is to gather scientific data on the magnetosphere in three dimensions. Cluster is composed of four nearly identical $1200 \mathrm{~kg}$ satellites placed into eccentric polar orbits with a semi major axis of about 12 Earth radii. Cluster does not employ controlled formation flight, but rather falls in the free flying category, where only stationkeeping propulsion is required. A tetrahedron formation naturally occurs on a periodic basis as described in [10].

Similarly, NASA manages an ongoing program called the Earth Observation System (EOS), which currently coordinates 17 satellites performing various types of remote sensing and science missions with a few international partners, including ESA. The segment of the EOS most interesting to this research is referred to as the "A-train," which is a set of six satellites in the same $705 \mathrm{~km}$ sun-synchronous orbit. Of those, PARASOL, CALIPSO, CloudSat, and Aqua are closely spaced, with the smallest distance being $100 \mathrm{~km}$ between CALIPSO and CloudSat [11].

The $\$ 130$ million Space Technology 5 (ST5) program, launched on March 22, 2006, is a part of NASA's New Millennium Program [12]. The three-satellite constellation, each with a mass of $25 \mathrm{~kg}$, was designed to evaluate technologies that can be used in future missions, mainly for space weather. Fong presents the $\$ 55$ million FORMOSAT-3/ COSMIC (Constellation Observing System for Meteorology, Ionosphere, and Climate) program, launched on April 14, 2006, which is an international collaboration between Taiwan and the U. S. [13]. It is a constellation of six $69 \mathrm{~kg}$ satellites. 


\subsection{Emerging Distributed Satellite Systems}

There has been a literary explosion of DSS related topics in the past ten years. For example, the terms distributed satellite systems, satellite formation flying, and satellite cluster have become very hot topics in publications of the American Institute of Aeronautics and Astronautics (AIAA), as highlighted in Table 1. The term satellite cluster is a surprisingly old phrase which originally described placing communication satellites at very close distances in Geostationary orbit (GEO) to address the crowding issue or provide more capacity.

\begin{tabular}{|cccc|}
\hline Year & $\begin{array}{c}\text { "Distributed } \\
\text { Satellite Systems" }\end{array}$ & $\begin{array}{c}\text { Satellite "Formation } \\
\text { Flying" }\end{array}$ & "Satellite Cluster" \\
$<1991$ & 0 & 0 & 19 \\
$1991-1995$ & 0 & 0 & 9 \\
$1996-2000$ & 27 & 16 & 23 \\
$2001-2006$ & 45 & 95 & 92 \\
\hline
\end{tabular}

Table 1. DSS Terms in AIAA Publications as of September 2006

Considering communication missions, Ashford notes that current realities have shattered all the previous predictions of a boom in low Earth orbit (LEO) based communications DSMs [14]. For example, a large-scale DSS for communication that never materialized was Teledesic. With conceptual designs ranging up to 840 satellites costing $\$ 5$ million each, Teledesic was to provide the first global "internet in the sky." The Teledesic mission was abandoned after witnessing the technical successes and economic failures of the IRIDIUM, Globalstar, and ORBCOMM constellations. Recently, new life has been breathed into these constellations by emerging applications that have encouraged investors to consider supporting replenishment of the constellation as they age.

Norris has proposed that clusters of small satellites operating in LEO will eventually be used to "virtually" replace larger monolithic telecommunication satellites [15]. There may be a demand for this someday as the GEO belt fills up, especially over the most populated areas of the Earth. Another variant of this idea, put forth by Edery-Guirardo, is to augment larger satellite missions with a constellation of smaller communication relay satellites [16]. For the near term, large satellites in GEO appear to be the mainstay of high-bandwidth global communications.

The GPS, GLONASS, and up and coming Galileo mission have already been categorized as constellations using ground links. Nowhere in the literature has anyone proposed using crosslinks or a cluster for navigation DSSs. In addition, current navigation systems have known vulnerabilities to jamming [17]. For the GPS system in particular, next generation systems will mitigate this vulnerability with the combination of higher power RF signals with other anti-jam technologies, causing the mass to rise from the current 1,000 $\mathrm{kg}$ to an estimated $1,500 \mathrm{~kg}$. The jamming environment will only get worse, requiring increased RF power from space. This trend does not facilitate the use of smaller systems.

There are numerous envisioned remote sensing DSSs; however, none of them has gone beyond the conceptual or experimentation phase. Examples of missions, which require real-time, distributed, multi-point sensing, are listed next. These mission ideas are based on the literature and suggestions formulated by the Surrey Space Centre (SSC) and SSTL.

- Volcano, fire, or Earthquake pre-emptive warning and detection

- Treaty monitoring (Kyoto Protocol, frequency, nuclear, other)

- Distress beacon monitoring

- Space control, signal intelligence, and other military missions [18]

- In particular imaging with frequent temporal repeats and high spatial resolution

- Constellation sharing where contributing members access the services of the entire group

- Disposable, short-lived rapid-response sensor networks for use in LEO and the upper atmosphere [19]

Reconfigurability of the satellite nodes would be required for more advanced missions, such as:

- Beam forming to remotely sense a particular location at optical or radio wavelengths

- Minimize power expenditure by dynamically optimizing RF links

The TechSat 21 idea, led by Das, is arguably the pathfinder technology proposal suggesting a formation flying cluster could be used for a mission such as space based radar [20]. Similarly, multistatic radar may also be possible. Clusters of co-orbiting assistants/inspectors of larger satellites, the space shuttle, or the International Space Station (ISS) are suggested by Macke [21].

Science and exploration missions have traditionally been dominated by single-spacecraft or interplanetary probe architectures due to characteristically limited science budgets and resources. There are a number of missions that are only now being envisioned as possible, due to the emergence of small satellites during the past couple of decades. Examples of missions that require real-time, distributed, multi-point sensing are listed below, where only those mission ideas that require a large constellation of low-cost mass-producible satellite nodes are referenced.

- Magnetotail behavior, solar wind variations, and other Geospace science [22]

- Interplanetary exploration based on satellite-on-a-chip [23]

- Monitoring and warning of large area space phenomena, mainly space weather, including plasma and radiation density [24]

- Monitoring wide-area highly time dependant phenomena, such as atmospheric drag or Aurora in LEO

- Detailed characterization of environments to support interplanetary exploration, such as Mars, asteroids, or other planets

- Upper atmosphere monitoring, e.g. $\mathrm{CO}_{2}$ levels at $60-250 \mathrm{~km}$

Reconfigurability of the satellite nodes would also be required for more advanced missions, for example:

- Measuring ion or electron scale space weather events and effect within the magnetosphere (10s of meters to km's)

- Compensating for interference from other sources such as radiation (lightning, trapped radiation e.g. South Atlantic Anomaly, stray electromagnetic fields) by frequency hopping

NASA's Terrestrial Planet Finder (TPF) mission is one of a few serious DSS cluster proposals for science and exploration that is currently being developed [25]. TPF will rely on a formation flying cluster at one of the Sun-Earth libration points to synthesize a very large aperture to see further in the universe than ever before. 
A simpler cluster mission proposed back in 2000 is to measure magnetic field variations around a spacecraft or perform visual inspection of the exterior for signs of damage. In addition, asteroid mapping and in-flight calibration of a communications beam pattern was suggested for clusters as well [22]. In 2001, the Orion-Emerald mission was proposed which was to demonstrate a cluster of three formation flying satellites [26]. The mission was due to fly in 2003 on the Space Shuttle. The mission concept has not re-emerged in the literature after the Columbia tragedy.

Overall, the problem of formation flying is very complex. Carpenter has outlined all the challenges associated with realizing formation flight [27]. Fully appreciating the magnitude of this problem, the focus of this research has been on DSMs based on constellations that require hundreds to thousands of satellites for real-time, distributed, multi-point sensing to accomplish long-awaited remote sensing and science objectives. Once enough of the formation flying problems are solved, perhaps very small satellite technology, reviewed the next section, could become a mission enabler.

\section{VERY SMALL SATELLITES}

Since the dawn of the space age in 1957, increasing mission requirements have driven up satellite mass from Sputnik's 84 $\mathrm{kg}$ to over $6,000 \mathrm{~kg}$ for some systems today. Consequently, cost, complexity, program timelines, and management overhead have grown considerably.

Reversing this trend, a fast-growing small satellite industry, rooted in academia, has enabled increasingly capable and costeffective space missions. Focusing on sub-500 kg satellites, their success is based on embracing smartly reduced requirements, integrating commercial technology, streamlining management structures, and using efficient engineering practices. In order to compare the capabilities of satellites, the space community in general has developed mass classifications as shown in Table 2 [28]. Mission costs are also listed, approximated by the author. The preponderance of missions has been in the minisatellite and microsatellite ranges as shown in Figure 2 [28].

Table 2. Satellite Categories by Mass and Approximate Costs

\begin{tabular}{|lll|}
\hline Large satellite & $>1000 \mathrm{~kg}$ & $\$ 0.1-2 \mathrm{~B}$ \\
Medium satellite & $500-1000 \mathrm{~kg}$ & $\$ 50-100 \mathrm{M}$ \\
Minisatellite & $100-500 \mathrm{~kg}$ & $\$ 10-50 \mathrm{M}$ \\
Microsatellite & $10-100 \mathrm{~kg}$ & $\$ 2-10 \mathrm{M}$ \\
Nanosatellite & $1-10 \mathrm{~kg}$ & $\$ 0.2-2 \mathrm{M}$ \\
Picosatellite & $100 \mathrm{~g}-1 \mathrm{~kg}$ & $\$ 20-200 \mathrm{~K}$ \\
Femtosatellite & $1-100 \mathrm{~g}$ & $\$ 100-20,000$ \\
\hline
\end{tabular}

Although minisatellites and microsatellites represent the largest segment of small satellite missions as just shown in Figure 2, this research is focused on the downward trend from nanosatellites to picosatellites to femtosatellites. Some have even humorously suggested a zeptosatellite class, which would be less than one gram. Looking closer, a mass histogram of all the sub-10 kg missions is given in Figure 3 [28]. Note that no nanosatellites were flown before 1990, and due to the multiplicity of several data points, 29 nanosatellite missions have flown.

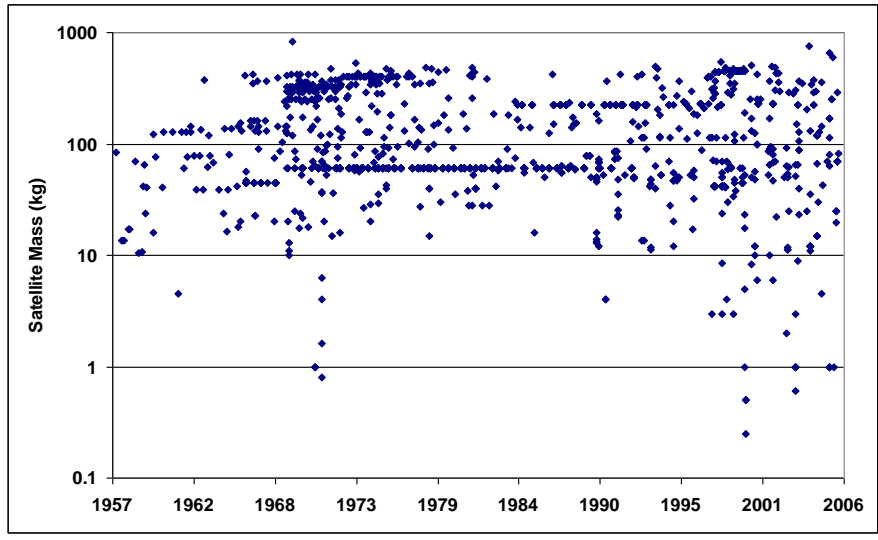

Figure 2. Small Satellite Mass Histogram

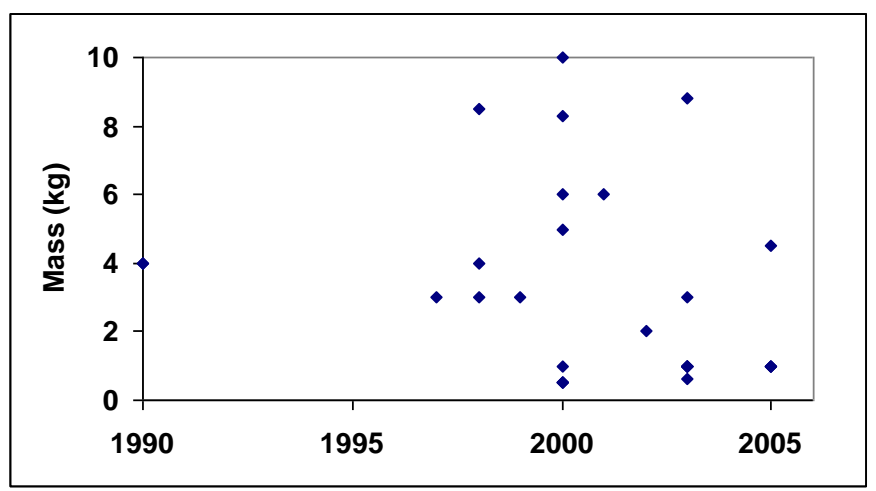

Figure 3. Very Small Satellite Mass Histogram

\subsection{Nanosatellites}

Although not included in the sub-kilogram VSS classification developed in this work, it is important to understand the capabilities and level of research in the nearest neighboring category of nanosatellites. As shown in Figure 3, 29 nanosatellites have flown, with the first one in 1990. Nearly all performed science or academic missions. The most capable nanosatellite flown to date was the $\$ 2$ million SNAP-1 mission back in 2000 with a mass of $6.5 \mathrm{~kg}$. Designed and built by SSTL in only nine months, it was the first nanosatellite to demonstrate the complete set of satellite functions typically found in larger satellites, including full attitude and orbit determination and control [29].

There are two notable recent and ongoing nanosatellite concepts. The first one is the recently renamed MicroLink-1 effort [30]-[31]. MicroLink-1 was originally envisioned at Uppsala University in Sweden and now is being further developed by a spin-off company, Ångström Aerospace Corporation. The spacecraft system architecture is based on multifunctional modules fabricated using a custom multi-chip module (MCM) process. The application of this approach for VSSs is discussed further in Section 3.4.

The other nanosatellite concept of note is an ongoing feasibility study, funded by ESA, titled "Nanosatellite Beacons for Space Weather Monitoring." The interim report does not yet give any details of a conceptual design or approximate costs, other than a $6 \mathrm{~kg}$ reference mission flown in 2000 [32]. The final report is scheduled for publication by the end of 2006. 


\subsection{Picosatellites}

Sixteen picosatellites have flown in the past ten years. The first picosatellites mission flew in 2000, which was dubbed the Orbiting Picosatellite Activated Launcher (OPAL) [33]. Eight custom-built picosatellites were deployed, but only Picosat 1 \& 2 were functional. The working pair was a Defense Advanced Research Project Agency (DARPA) mission to investigate picosatellites. They carried small experiments powered by a primary battery and successfully transmitted their data to Earth. They were tethered together and were considered one space object. Later in 2000, a second pair of DARPA picosatellites (Picosat $7 \& 8$ ) were supposed to be jettisoned from a host satellite called "MightySat." It is believed that separation did not occur, but cannot be verified.

The eight most recent picosatellite missions were "CubeSats," which is a university student satellite standard defined by Stanford University and California Polytechnic Institute. CubeSat has addressed some important issues by reducing the complexity of satellite design, especially the launch vehicle separation system [34]. CubeSats are now available as a commercial kit that gives students a basic structure and flight computer for about $\$ 5,000$. The design concept is essentially a scaled-down version of larger satellite designs using miniaturized modules. The payload and all other subsystems must be supplied by the user, usually resulting in an average cost of $\$ 75,000$. New companies are emerging to supply the CubeSat market, such as Clyde Space, which provide electrical power subsystems [35]. In 2003, the Eurockot launch deployed the first five CubeSats, but only three were declared successful. Again, in 2005, the SSETI Express deployed three more CubeSats, with two being successful. Overall, picosatellites have a $50 \%$ success rate. These missions are summarized in Table 3. Unfortunately, 14 new CubeSat systems were destroyed by a launch vehicle failure in July 2006. Another launch is planned for late September 2006.

Table 3. Summary of All Picosatellite Missions to Date

\begin{tabular}{|cccc|}
\hline Mission & Satellite & Bus & Status \\
\hline OPAL 2000 & Picosat 1 \& 2 & Custom & Success \\
& Thelma & Custom & Failed \\
& Louise & Custom & Failed \\
& JAK & Custom & Failed \\
& Stensat & Custom & Failed \\
\hline MightySat 2000 & Picosat 7 \& 8 & Custom & Status Unknown \\
\hline Eurockot 2003 & CubeSat-XI-IV & CubeSat & Success \\
& DTUSat & CubeSat & Failed/Unknown \\
& CUTE-I & CubeSat & Success \\
& CanX-1 & CubeSat & Failed/Unknown \\
& AAU CubeSat & CubeSat & Short Life/Power \\
\hline SSETI 2005 & CubeSat XI-V & CubeSat & Success \\
& UWE-1 & CubeSat & Success \\
& Ncube-2 & CubeSat & Failed/Unknown \\
\hline
\end{tabular}

One notable picosatellite that has been in development at SSC since the success of the SNAP-1 nanosatellite is PalmSat [36]. PalmSat is an independent design from CubeSat and hopes to offer more capability with deployable solar arrays. It is configured for single-ship missions focused on science, with the possibility of operating in a distributed environment. Its development is currently advanced by students' research projects and is based on conventional miniaturization.

\subsection{Femtosatellites}

To date, no femtosatellite has ever been launched into space. Helvajian and Janson pioneered a femtosatellite design for spacecraft inspection based on a glass/ceramic structure and Microelectromechanical Systems (MEMS) sensors in 2002 [37]. Their femtosatellite design focuses on the propulsion and structural subsystems, which is discussed further next. Cyrospace claims to have designed a femtosatellite, but attempts by the author in contacting the company or identify published documentation have turned up negative [38].

\subsection{Emerging Very Small Satellite Fabrication Technologies}

Since 1998, Helvajian and Janson, both working for the Aerospace Corporation, El Segundo, California, have pioneered the idea of microengineering of aerospace systems [39]-[40] and have published several recent works on various VSS concepts based on MEMS and microfabrication [41]. One of the earliest concepts was an "all silicon" approach, where satellites are envisioned to be mass-produced using a stack of payloads and subsystems built on silicon wafers [42]. In addition to MEMS, its integration with CMOS is essential [43] in the development of technologies specifically targeted at developing VSSs [44].

As was just introduced in the previous section, Janson and Helvajian developed the satellite inspector concept, proposed initially with a $100 \mathrm{~g}$ mass baseline [37]. The concept has been recently revised, targeting a one kilogram configuration [45]. Their work is mostly focused on propulsion and structure, with some initial thoughts on the other required subsystems. According to [45], seven wafers made of Foturan $^{\mathrm{TM}}$, which is a glass/ceramic material that can be restructured using a laser, require 20 hours of processing each, totaling 140 hours for one satellite. This is in addition to the assembly required for the conventional PCB "wafer" for the electronics. No costs are published, but is appears that a significant amount of investment has been put into this new manufacturing technology.

Xuwen and later Shul, published similar concepts in 1998 and 2000, but no follow-on effort has emerged [46]-[47]. In parallel, the concept of multifunctional structures and architectures emerged, backing the idea of low-cost mass production of satellites [48]. This approach fostered the responsive space movement [49], proposing that satellites could be built and deployed rapidly using streamlined manufacturing processes and modular technologies [50].

Previously mentioned in the nanosatellite discussion, Bruhn, of the Ångström Aerospace Corporation, has led an effort to reduce satellite mass and volume by "orders of magnitude" [30]-[31]. His team's approach is based on a new architecture called Multifunctional Micro Systems (MMS), which uses standardized MCMs that make heavy use of MEMS. Recently, their technology was licensed by the newly formed CANEUS NPS (nano-pico-satellite) Incorporated [51]. Their goal is to start mass-production of nanosatellites in three years for $\$ 4$ million each that have the capability of present-day microsatellites. Picosatellites will be offered for $\$ 2$ million. 
Another emerging femtosatellite concept, first discussed in the literature in 1994, is satellite-on-a-chip [52]. Over twenty references in the literature have used this term, but no serious effort has been undertaken to pursue the idea until 2005 when the author first proposed the SpaceChip concept [2].

The aim of the SpaceChip project is to implement a monolithic "satellite-on-a-chip" using commercial CMOS technology. The undertaken conceptual design showed that a unit cost of less than $\$ 1000$ could be achieved, which is supported by more than twenty references to recent work that directly support the SpaceChip idea. The conclusion from this work is that such an approach, although entirely possible, is limited by the current on-chip antenna technology, achieving a very short communication range of only $5 \mathrm{~m}$ [3].

During the process of designing SpaceChip, a risk-reduction strategy of developing a satellite-on-a-printed circuit board (PCB) prototype of a femtosatellite was accomplished in parallel. The original purpose of this approach was to develop the architecture by integrating single-chip solutions for the payload and subsystems on a PCB. As the design emerged, it became apparent that it could potentially enable a class of missions that require real-time, distributed, multipoint sensing. In addition, the concept relies nearly entirely on commercially available components, PCB manufacturing, and assembly, yielding a prototype unit cost of $\$ 300$ as detailed in Section 4.

\subsection{Relative Complexity Versus Cost Comparison of VSS Approaches}

Comparing the complexity and cost of competing VSS technologies is challenging at this stage of research due to the differing maturity of each technology. However, an effort has been made to compare the relative complexity vs. cost of these technologies and is purely the opinion of the author.

Relative complexity is roughly gauged on the combined perception of the manufacturing technology maturity and the flexibility to adapt the design for various mission scenarios. The relative cost is based more on solid data for each technology, with the exception of the efforts at The Aerospace Corporation and Ångström Aerospace Corporation, which are assumed to be the most expensive at their respective stages of process development. Figure 4 compares the relative complexity vs. cost of the four technology areas discussed.

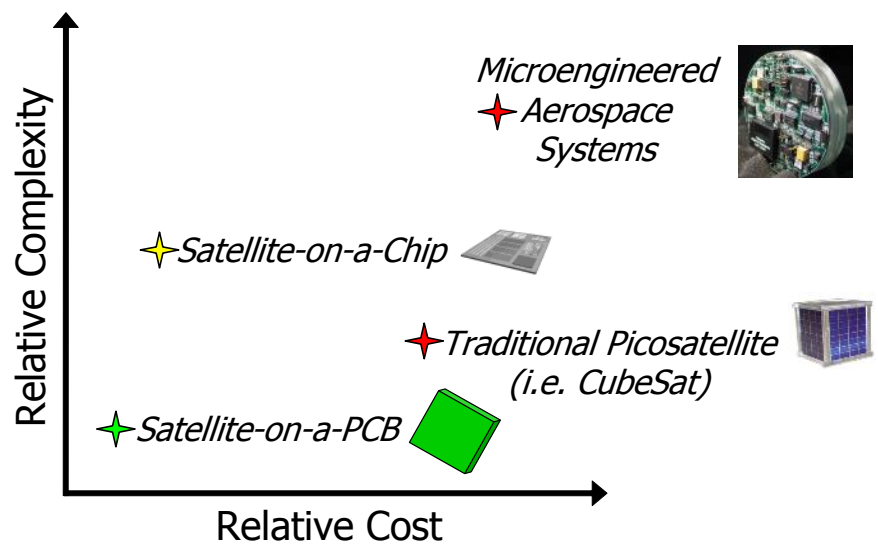

Figure 4. Very Small Satellite Complexity vs. Cost Comparison

\section{SATELLITE-ON-A-PCB DESIGN}

Realizing that the available VSS technologies rely on laborintensive or custom manufacturing processing, the author initially investigated the satellite-on-a-chip approach, which leverages the commercial availability of CMOS foundries. While this technology is still considered worthwhile to pursue, SpaceChip's range of applications has proved to be very limited, even with an attractive unit cost of only $\$ 1000$.

In parallel to the SpaceChip feasibility study [2]-[3], a rapid PCB prototype of a femtosatellite was envisioned to help guide the SpaceChip architecture. The original goal was to determine how much satellite capability could be squeezed into a $100 \mathrm{~g}$ package. Now that the concept is envisioned for spaceflight, the challenges of the space environment and mission architecture must be addressed in the next phase of the project and are discussed further in Section 6.

The author's experience as the team lead and one of the designers of EyasSAT inspired the idea [53]-[55]. EyasSAT is a $2.5 \mathrm{~kg}$ modular, expandable educational satellite system that facilitates hands-on teaching and learning of satellite systems engineering in a classroom environment. EyasSAT is currently in the U.S. "Patent Pending" status. The project name "PCBSat" was coined for the satellite-on-a-PCB design, merging the two ideas. PCBSat is a completely new design and therefore does not contain any of the patent pending intellectual property of EyasSAT. The two main goals for the project are to:

- Guide the SpaceChip architecture design by prototyping with commercial components

- Function as a complete standalone femtosatellite that could be space qualified

During the design process, two spin-off goals were realized:

- Offer a payload module option for EyasSAT

- Experiment with improvements for the next EyasSAT design

\subsection{System Description}

The goal of the PCBSat design was to determine what capabilities could be incorporated in a $100 \mathrm{~g}$ femtosatellite with commercial components and fabrication technologies. The system requirements mirror those for SpaceChip-the envisioned mission architecture would be a dispersed constellation of femtosatellites operating as a DSS to provide the capability for real-time, simultaneous, multipoint sensing. Similar to SpaceChip, Space Mission Analysis and Design principles were used throughout the design of PCBSat [56]. However, the PCBSat design was a "bottom's up" approach, where a finite set of payload and subsystem components, constrained by commercial parts availability, were integrated to determine the overall system capability, which in turn, determined its range of applications.

The design process became fairly simple by imposing a few constraints for simplicity:

- Use familiar Atmel, Dallas, and Maxim IC products

- Use surface-mount components as much as possible

- Maintain EyasSAT compatibility by using the PC104 form factor and EyaBUS standard, which defines the data and power interface 
After two design revisions, a final system configuration was reached. The basic outline follows with key components:

\section{Payload}

- 640x480 CMOS imager (ST Microelectronics VS6502)

\section{Configuration and Structure}

- Mass less than $100 \mathrm{~g}$

- Single 4-layer PCB measuring 9.0x9.5 cm (PC104 standard)

- Module function determined by component population

Electrical Power Subsystem (EPS)

- 7-cell solar array using $\$ 5$ silicon hobby cells

- Peak power tracking (PPT) circuit (MAX856/982)

- 645 mAh Lithium-Ion battery

- Battery charge regulator (BCR) (MAX856/982)

- Regulated 3.3V system power supply (MAX604)

- Telemetry: voltage and current measurements for battery, solar array, and regulated supply (MAX471), and separation

Data Handling (DH)

- Reduced instruction set (RISC) microcontroller running at the minimum frequency to support $115.2 \mathrm{kbps}$ data rates (Atmel Mega128L, 3.3V, $4 \mathrm{MHz}, 128 \mathrm{~K}$ flash, 4K SRAM)

- CMOS-level umbilical (Acroname USB CMOS converter)

- In-system programmable (Atmel AVRISP dongle)

- Serial peripheral interface (SPI) link for EyasSAT payload

- Telemetry: real-time clock with battery backup (DS1302Z)

Communication (Comm)

- $2.4 \mathrm{GHz}, 60 \mathrm{~mW}$ RF ZigBee module (MaxStream XBeePro)

- Telemetry: received signal strength indication (RSSI)

Attitude and Orbit Determination and Control (AOCS)

- iTrax-03S single-module GPS receiver and Sarantel antenna

- Single-axis magnetorquer

- Telemetry: front and back "digital" (light/dark) sun sensors

Thermal

- Telemetry: solar cell and battery temperature

The computer-aided design (CAD) tool selected for this project was EAGLE from CadSoft. It is PC based, very inexpensive, easy to use, and has an extensive parts database. The final Gerber PCB layer files were inspected for errors with the Pentalogix Viewmate viewer tool. The PCBs were then produced at a commercial facility in prototype quantities.

The selected payload is the ST Microelectronics VS6502 color CMOS imager with integrated lens. It has a two-wire $\left(\mathrm{I}^{2} \mathrm{C}\right)$ control and 5-wire data interfaces. A picture of the device and basic specifications are shown in Figure 5. The device snaps into a surface-mount socket mounted on the PCB or at the end of a remote-cable for mounting on the top of the EyasSAT system when in payload configuration.

- 640x480 (VGA) pixel resolution

- 30 frames/sec video or still shots

- $5.6 \mu \mathrm{m}$ x $5.6 \mu \mathrm{m}$ pixel size

- $2.05 \mathrm{~V} / \mathrm{lux}-\mathrm{s}$ sensitivity

- $+37 \mathrm{~dB}$ signal/noise ratio

- 2.6 to $3.6 \mathrm{~V}$ supply voltage

- $<30 \mathrm{~mA}$ current draw when active

- 0 to $40{ }^{\circ} \mathrm{C}$ operating temperature

- 11x9x6 mm package size

- 14 pad SmOP package

- $47^{\circ}$ field of view, f\#2.8

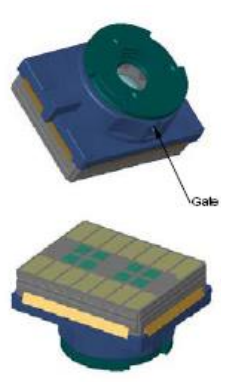

Figure 5. ST Microelectronics VS6502 CMOS Imager
The initial design of PCBSat has been purposely confined to a single PC104 form factor configuration. The next phase of the project will be a complete space systems engineering approach [56], addressing the structure [57] and space environment issues. These are discussed in Section 6 of this paper.

Satellites are typically composed of numerous subsystems to support the payload. It is essential to have the following subsystems: EPS, DH, Comm, and thermal control. Optionally, mission and payload requirements may call for ADCS, OCS, and/or propulsion subsystems. The following sections review the basic design of the required subsystems.

\subsection{Electrical Power Subsystem}

A spacecraft EPS is typically composed of four basic functions: power source, energy storage, power distribution, and power regulation and control [56]. The basic EPS design of PCBSat is to utilize primary solar power, secondary rechargeable batteries, and deliver $3.3 \mathrm{~V}$ regulated power.

Solar energy was the obvious choice for the primary power source. The most efficient hobby-grade solar cells that can be readily purchased are $15 \%$ Silicon $(\mathrm{Si})$, measuring $2 \times 4 \mathrm{~cm}$. They have an advertised peak power output of $0.484 \mathrm{~V}$ at 250 $275 \mathrm{~mA}$. The back side of the PC104 PCB is available for solar cell mounting. Leaving space for a few parts that require mounting through-holes (vias), only seven can be mounted.

To extract the maximum power out of the solar array, peak power tracking (PPT) was selected over the less complex, but inefficient direct energy transfer (DET) choice. This method places a smart interface between the solar array and battery to extract the maximum amount of power out of the solar array over a range of solar conditions. The baseline design was chosen from a Maxim application note on their website as shown in Figure 6 [58].

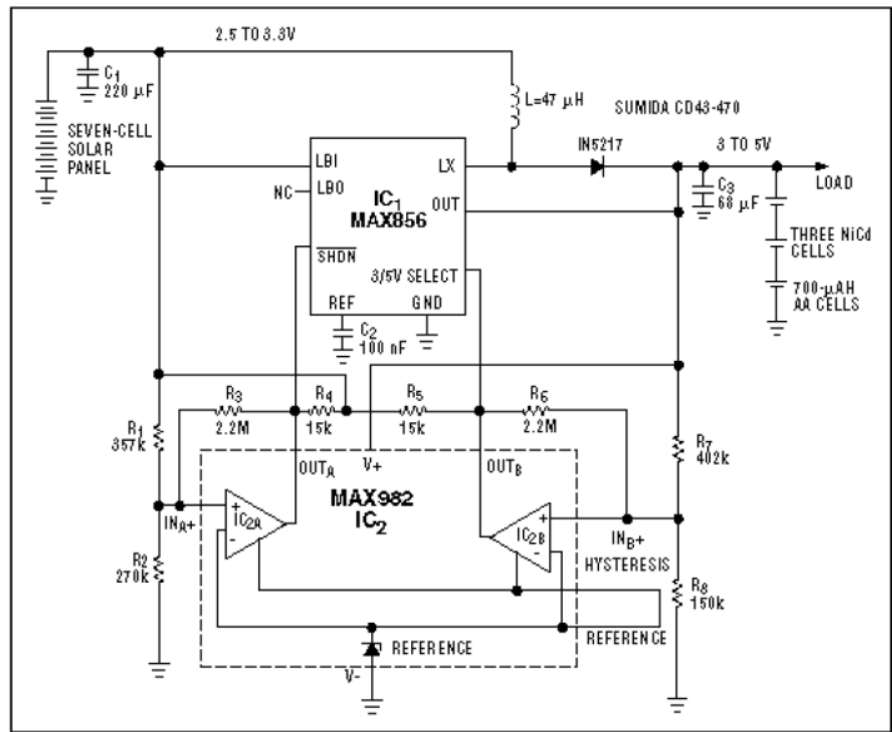

Figure 6. Maxim PPT and BCR Circuit

The Maxim design example suggests using an array of seven solar cells with the same specifications of the hobby-grade cells selected previously, which is a convenient coincidence. The principle of operation is simple. As charge from the solar array builds up on $\mathrm{C} 1$, the voltage is monitored by one of the voltage comparators on the MAX982 IC in Figure 6. When 
the voltage reaches the threshold $(2.9 \mathrm{~V})$, the MAX856 step-up DC-DC converter is powered up and converts the stored charge on $\mathrm{C} 1$ to $5 \mathrm{~V}$ power, which is enough to charge the battery, which has a nominal voltage of $3.6 \mathrm{~V}$. Although shown as nickel cadmium technology in Figure 6, a Li-Ion battery will be used, as discussed below. When the voltage on C1 falls below the lower threshold $(2.5 \mathrm{~V})$, the step-up converter is shut down. The cycle repeats and the battery is charged in pulses as long as there is solar energy.

A second important feature of a good EPS design is battery charge regulation (BCR). The Maxim circuit implements a BCR simply by using the second voltage comparator of the MAX982 IC to monitor the voltage level of the battery. When the battery charge reaches $4.6 \mathrm{~V}$, the MAX856 step-up converter is "shut down" by toggling the $3.3 / 5 \mathrm{~V}$ line to 3.3 , causing the battery to charge at $3.3 \mathrm{~V}$, which in effect renders the step-up converter ineffective, as it is below the nominal battery voltage of $3.6 \mathrm{~V}$.

Selecting a suitable battery was surprisingly difficult due to the finite types of physical battery configurations. Originally, a $3.6 \mathrm{~V}, 80 \mathrm{mAh}$ nickel-metal hydride (NiMH) used for PC memory backup was chosen. In the end, it did not have enough capacity, so the higher density Li-Ion technology was chosen. A $645 \mathrm{mAh}$ pack designed for a digital camera was chosen with the ideal dimensions.

The final major EPS component is power regulation. Efficient satellite EPS designs use DC-DC converters, which offer efficiencies greater than $90 \%$. However, the MAX 604 linear regulator offers $92 \%$ efficiency when stepping down from $3.6 \mathrm{~V}$ to $3.3 \mathrm{~V}(3.3 / 3.6=92 \%)$.

Although not a major function, satellite EPS designs typically include a way to monitor the health and status of the system remotely, which is usually referred to as "telemetry." In this design, the most important telemetry points are the voltage and current of the solar array, battery, and the $3.3 \mathrm{~V}$ regulated power supply. These telemetry points are inherently analog, so an analog-to-digital converter (ADC) is required, which is discussed in the next section on Data Handling. In order to sample the voltage, simple resistor-based voltage dividers are used to scale the voltage points down to the operating range of the ADC. To sample the current, a voltage drop must be measured across a very low resistance resistor and then amplified using an operational amplifier. An elegant packaged solution for this circuit is the MAX471.

\subsection{Data Handling Subsystem and Software Development}

In order to leverage experience previously gained, the chosen heart of the DH subsystem is the Atmel Mega128 8-bit AVR® microcontroller. The 3.3V low-power Mega128L variant was selected for this project, with the key advantage being an advertised low current draw of less than $5 \mathrm{~mA}$ when operating at $3.6864 \mathrm{MHz}$. The Mega128L is in-system programmable (ISP), meaning that it can be programmed without having to be removed from the circuit. This is accomplished via a 6wire programming interface to an AVRISP ${ }^{\circledR}$ dongle with is connected to an RS-232 or USB port of a computer. The key features are outlined in Figure 7.
- Low-power 3.3V variant

- Up to $8 \mathrm{MHz}$ clock, $5 \mathrm{~mA} @ 4 \mathrm{MHz}$

- ISP flash programmable

- Boot-loader programmable

- $128 \mathrm{~K}$ flash memory

- 4K EEPROM and 4K SRAM

- $\mathrm{I}^{2} \mathrm{C}$ interface

- 53 multipurpose I/O lines

- Six counters/PWMs

- 8-channel 10-bit ADC

- Dual USART interface

- SPI interface

- Low-power sleep modes

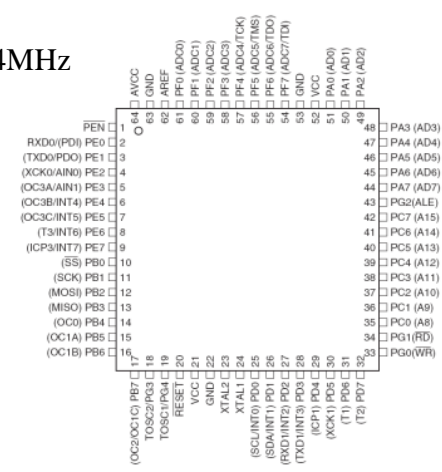

Figure 7. Atmel Mega128L Key Features

The $\mathrm{I}^{2} \mathrm{C}$ interface is used to control the CMOS imager payload. Four of the I/O lines are configured as inputs to read the pixel data nibbles. One of the $\mathrm{I} / \mathrm{O}$ lines is configured as a hardware interrupt to detect when pixel data is valid. Another $\mathrm{I} / \mathrm{O}$ line is configured as a high-speed pulse-width modulator (PWM) to drive the system clock of the imager. One more I/O line to the imager can put it in lower power mode.

The eight ADC channels are used to read the EPS and Thermal telemetry. Two other I/O lines are configured appropriately to collect the separation status and percent PPT.

One Universal Synchronous-Asynchronous Receiver Transmitter (USART) port configured at $115.2 \mathrm{kbps}$ is used either for a wired umbilical connection during development or to the XBee RF module. Four I/O lines control its state.

The other USART port configured at $4800 \mathrm{bps}$ interfaces with the GPS module. Six additional I/O lines control its state. Three other I/O lines control the magnetorquer and read data from the sun sensors.

Finally, the serial peripheral interface (SPI) is used only when the system is used as an EyasSAT payload. MAX3371 level shifters are used on the four-wire SPI connection to link together the $3.3 \mathrm{~V}$ and $5 \mathrm{~V}$ systems.

The Mega128L has 128K of non-volatile flash memory, which can be used for program and data storage. However, it is rated at 10,000 duty cycles, so using it for data storage should be kept to a minimum, as one read/write cycle counts as one duty cycle. $4 \mathrm{~K}$ of non-volatile electrically erasable/programmable read only memory (EEPROM) and $4 \mathrm{~K}$ of volatile static random access memory (RAM) is available for program use.

Software development for the project was relatively straightforward. CodeVisionAVR was selected as the software development environment, as it has a large user base and support community.

The software for the project was just over 1,300 lines of code written in the ANSI $C$ language. The compiled binary file is 7.5 kilobytes in size, taking $11 \%$ of the available code space.

A timer is used to run scheduled telemetry collection and reporting. Hardware interrupts are used to detect user commands through the umbilical or wireless links then decode and execute the command in the main subroutine. A significant amount of the code is used to detect and interpret the GPS module data, which arrives once a second. Similarly, the CMOS Imager requires a lot of the CPUs attention. 


\subsection{Communications Subsystem}

The PCBSat Comm subsystem is one of the key elements of the design, as the communication capabilities will directly influence potential DSS constellation designs. The two main drivers are low-power long-range communications and unlicensed operations. Unlicensed operations can be achieved by operating in one of the Industrial, Scientific, and Medical (ISM) RF bands. The $2.4 \mathrm{GHz}$ band was selected for this project, as it is legal to use in North America and Europe.

A single-chip RF solution was sought, as this mirrors the work that will take place with SpaceChip. The Atmel ATR2406 ISM Transceiver was used on the first revision of the PCB. Atmel provided excellent technical support, software examples, and an initial PCB layout. In the end, it required too many external components, the Micro Lead Frame (MLF)type packaging was too hard to solder by hand, and the transmission range was found to be less than $100 \mathrm{~m}$.

Two potential solutions emerged on the market after the first design was completed. The MaxStream XBee module is a ZigBee/IEEE 802.15.4 commercial integrated module. Two types are available, the low-power XBee and the high-power XBee Pro. The XBee Pro is the best option as it offers an improved electrical-to-RF transmission efficiency of $6.7 \%$ and a range of about $1,335 \mathrm{~m}$. A radio with more range will be needed when the mission architecture is better defined, such as the MaxStream XTend transceiver, which has an advertised maximum terrestrial range of $65 \mathrm{~km}$ with a very high $\mathrm{RF}$ efficiency. A comparison of all four transceiver technologies is shown in Figure 8.

\begin{tabular}{|l|c|c|c|c|}
\hline Specification & ATR2406 & XBee & XBee Pro & XTend \\
\hline Vendor & Atmel & MaxStream & MaxStream & MaxStream \\
\hline Cost & $\$ 8$ & $\$ 19$ & $\$ 32$ & $\$ 179$ \\
\hline PCB area & $3 \times 6 \mathrm{~cm}$ & $2.4 \times 2.8 \mathrm{~cm}$ & $2.4 \times 3.3 \mathrm{~cm}$ & $3.7 \times 6.05 \mathrm{~cm}$ \\
\hline Mass & $1 \mathrm{~g}$ & $3 \mathrm{~g}$ & $4 \mathrm{~g}$ & $18 \mathrm{~g}$ \\
\hline Software required & $50 \% \mathrm{CPU}$ use & No & No & No \\
\hline External parts & $21 \&$ custom PCB & 0 & 0 & 0 \\
\hline Max data rate & $122.88 \mathrm{kbps}$ & $115.2 \mathrm{kbps}$ & $115.2 \mathrm{bps}$ & $115.2 \mathrm{bps}$ \\
\hline RF Power & $2.5 \mathrm{~mW}(4 \mathrm{dBm})$ & $1 \mathrm{~mW}(0 \mathrm{dBm})$ & $60 \mathrm{~mW}(18 \mathrm{dBm})$ & $0.5 \mathrm{~W}(27 \mathrm{dBm})$ \\
\hline Range & $\sim 300 \mathrm{~m}$ & $258 \mathrm{~m}$ & $1335 \mathrm{~m}$ & $>50 \mathrm{~km}$ \\
\hline Receive current & $57 \mathrm{~mA}$ & $50 \mathrm{~mA}$ & $55 \mathrm{~mA}$ & $80 \mathrm{~mA}$ \\
\hline Transmit current & $42 \mathrm{~mA}$ & $45 \mathrm{~mA}$ & $214 \mathrm{~mA}$ & $600 \mathrm{~mA}$ \\
\hline Transmit efficiency & $1.3 \%$ & $0.67 \%$ & $6.7 \%$ & $25.3 \%$ \\
\hline
\end{tabular}

Figure 8. Comparison of ISM Transceivers

\subsection{Attitude and Orbit Determination and Control Subsystem}

Due to the mass, size, and power constraints of the proposed design, very limited AOCS options were available for PCBSat. For attitude determination, two cadmium sulfide (CdS) sensors, one on the front and the other on the back, are used to tell which face of the PCB is illuminated. For attitude control, a high-current p-type field-effect transistor (pFET) is used to power a magnetorquer coil, which is activated by one of the PWM channels, so its duty cycle can be adjusted.

The first PCB revision did not include any considerations for orbit determination and control (OCS). While evaluating potential mission applications, it became apparent that for many missions, a key enabler is to know where the satellite is when the potential payload collects data.

The obvious solution is a GPS receiver. Since the start of this project, two GPS modules that are small enough to fit on this design were introduced on the market. The Fastrax iTrax-03S and Trimble Copernicus are surface mount packages measuring less than $20 \times 20 \times 3 \mathrm{~mm}$ only require an external antenna and filtered power. The Fastrax module was chosen as it was readily available through common distributors, while the release of the Trimble module has been delayed. Sarantel offers an excellent miniature passive surface mount antenna.

For actual space application, terrestrial GPS receivers, such as the Fastrax module cannot be used as-is. Due to the orbital velocity of about $7.5 \mathrm{~km} / \mathrm{s}$ in low Earth orbit, the receiver firmware must be modified. This problem has been well documented and solutions reported on Error! Reference source not found.

\subsection{Thermal Control Subsystem}

The thermal environment is one of the most challenging issues in spacecraft systems engineering. As mentioned previously, design work to date has not taken the thermal aspect of the space environment into account. However, to implement a minimal TCS, temperature telemetry points were essential. Since six ADC ports are used by the EPS, two ports remained. The spacecraft components that are the most crucial to monitor for temperature are the solar array and battery.

\section{ASSEMBLY, INTEGRATION, AND TEST RESULTS}

The assembly of PCBSat was straightforward. All components were hand-soldered by the author, with the exception of the GPS module, which required the help of a soldering technician. Satellite "integration" at this scale of design is inherent, as the entire spacecraft is on one PCB. Pictures of the second revision of PCBSat are shown in Figures 9 and 10.

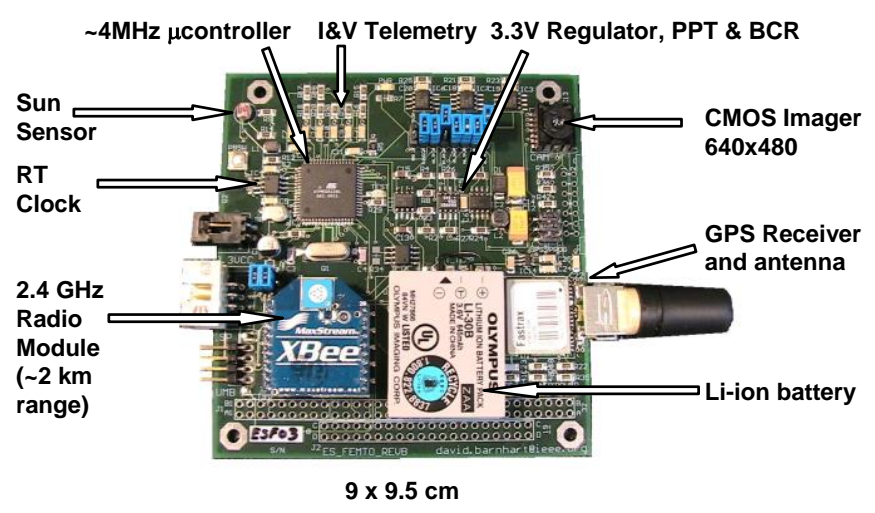

Figure 9. Front Side of PCBSat

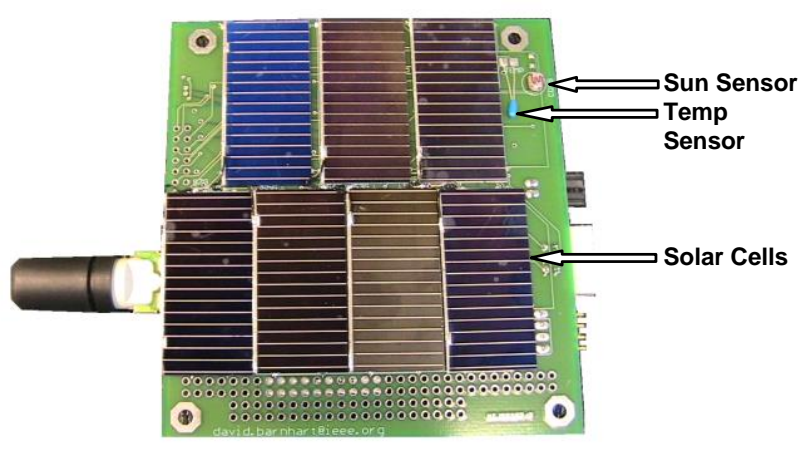


Figure 10. Back Side of PCBSat

The first PCB design of PCBSat did not allow for testability of all points without incrementally building it up. Applying that lesson learned, the second revision allows for isolation and testing of all subsystems on the PCB after it is completely populated with all parts.

Acceptance testing was limited to the inspection of the commercial parts and the custom PCB. Some parts were ordered early for a "paper-fit" on a to-scale printout of the PCB. When the PCB was received, it was compared to the printout and simple electrical tests were performed, mainly to ensure that the power and ground lines were not shorted, nor connected to any other important signal or power lines.

Functional testing and component characterization were performed on each component as appropriate. A summary of functional test results are given in Table 4.

Table 4. Functional Test Results in Order of Completion

\begin{tabular}{|l|c|c|}
\hline \multicolumn{1}{|c|}{ Test } & Expected & $\begin{array}{c}\text { Measured/ } \\
\text { Observed }\end{array}$ \\
\hline GPS lock & $33 \mathrm{sec}$ & $27 \mathrm{sec}$ \\
\hline CPU ISP programming & Pass & Pass \\
\hline CPU clock frequency & $3.6864 \mathrm{MHz}$ & 3.6864 \\
\hline UMB link to PC & Pass & Pass \\
\hline CPU read GPS @ 4800 bps & Pass & Pass \\
\hline EyasSAT SPI interface & Pass & Pass \\
\hline RF comm link @ 115.2 kbps & Pass & Pass \\
\hline RT clock frequency & $32.768 \mathrm{kHz}$ & 32.767 \\
\hline RT clock/backup & Pass & Pass \\
\hline Thermistor readings (2) & Pass & Pass \\
\hline Sun sensor readings (2) & Pass & Pass \\
\hline Torque rod activation & Pass & Pass \\
\hline EPS voltage regulation & $3.3 \mathrm{~V}$ & $3.29 \mathrm{~V}$ \\
\hline EPS voltage telemetry (3) & Pass & Pass \\
\hline EPS current telemetry (3) & Pass & Pass \\
\hline Solar array output & $0-3.39 \mathrm{~V}$ & Pass \\
\hline EPS Peak Power Tracking & Pass & Pass \\
\hline EPS Battery Charge Reg. & Pass & Pass \\
\hline CMOS Imager & Pass & Pass \\
\hline
\end{tabular}

The following sections summarize the testing and results of the payload and subsystems beyond functional testing. Some components required straightforward testing, checking if the circuit is functional, while others required a characterization over time, or varying conditions.

\subsection{Payload Test Results}

The payload is the CMOS Imager. The imager was able to be switched on by command from the CPU. It was originally not clear from the documentation what clock frequency was needed by the imager. After experimenting with several values, it was found that a clock of $6 \mathrm{MHz}$ was required. This was able to be provided by one of the high-speed PWM channels of the CPU. The imager must have a system clock to accept configuration commands on the $\mathrm{I}^{2} \mathrm{C}$ bus and generate pixel data on the data bus. The imager was programmed to take a still image at $320 \times 240$ pixels. The current draw was 30 $\mathrm{mA}$ maximum during image capture.

\subsection{Structure and Configuration Test Results}

The current system mass is $70 \mathrm{~g}$, which is below the $100 \mathrm{~g}$ limit set for the project, but does not include a structure suitable for spaceflight. Future structural development is discussed further in Section 6.

\subsection{EPS Test Results}

The EPS had the most testable points of all the subsystems. Table 5 presents the results. The only significant deviation from the expected results is the operating point of the PPT/Solar Array as found in Figure 11. The logical explanation is that the expected results are based on a "one sun" test of the results which best approximates solar conditions, while the result found here was from an indoor test using a 500W halogen lamp, which is not full-spectrum. Even so, the EPS is able to deliver an average of $487 \mathrm{~mW}$, when the average power requirement of the system is $365 \mathrm{~mW}$, which includes battery charging. These numbers were calculated using standard SMAD equations [56] as shown in [3].

Table 5. EPS Characterization Results

\begin{tabular}{|l|c|c|}
\hline \multicolumn{1}{|c|}{ Test } & Expected & $\begin{array}{c}\text { Measured/ } \\
\text { Observed }\end{array}$ \\
\hline Regulator efficiency & $92 \%$ & $92 \%$ \\
\hline PPT/BCR efficiency & $80 \%$ & $82.7 \%$ \\
\hline PPT charge threshold & $2.9 \mathrm{~V}$ & $2.95 \mathrm{~V}$ \\
\hline PPT drain threshold & $2.5 \mathrm{~V}$ & $2.63 \mathrm{~V}$ \\
\hline PPT operating point & $3.4 \mathrm{~V}, 250 \mathrm{~mA}$ & $2.6 \mathrm{~V}, 265 \mathrm{~mA}$ \\
\hline
\end{tabular}

Table 6. PCBSat Power Budget (* items duty cycled)

\begin{tabular}{|l|c|c|c|}
\hline Subsystem & Typical & $\begin{array}{c}\text { Typical } \\
(\mathbf{m W})\end{array}$ & $\begin{array}{c}\text { Actual } \\
(\mathbf{m W})\end{array}$ \\
\hline Payload & $40 \%$ & 26 & $10^{*}$ \\
\hline EPS & $15 \%$ & 10 & 1.3 \\
\hline DH & $10 \%$ & 7 & 18 \\
\hline Comm & $30 \%$ & 20 & $170^{*}$ \\
\hline ADCS & $5 \%$ & 3.3 & $130^{*}$ \\
\hline Total: & $\mathbf{1 0 0 \%}$ & $\mathbf{8 6}$ & $\mathbf{3 3 0}$ \\
\hline
\end{tabular}

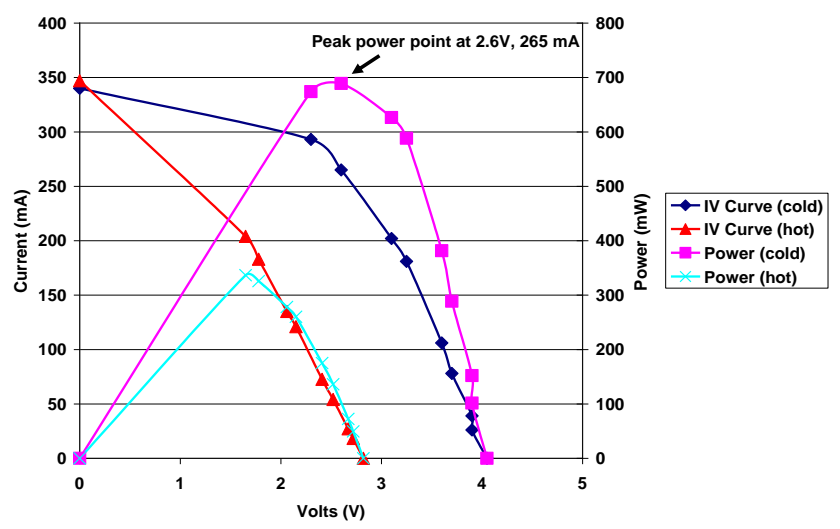


Figure 11. PCBSat Solar Array IV Curve Results

As mentioned in the design section, the original battery used was an $80 \mathrm{mAh} 3.3 \mathrm{~V} \mathrm{NiMH}$ battery, which was not sufficient. The Olympus Li-30B battery selected performed much better. Simulating a full system load in eclipse, the battery was fully charged then discharged at a $55 \mathrm{~mA}$ system load. The battery was able to operate for about six hours before it reached the "knee," which is the rapid drop off point that no rechargeable battery technology is designed to operate in. The results are shown in Figure 12.

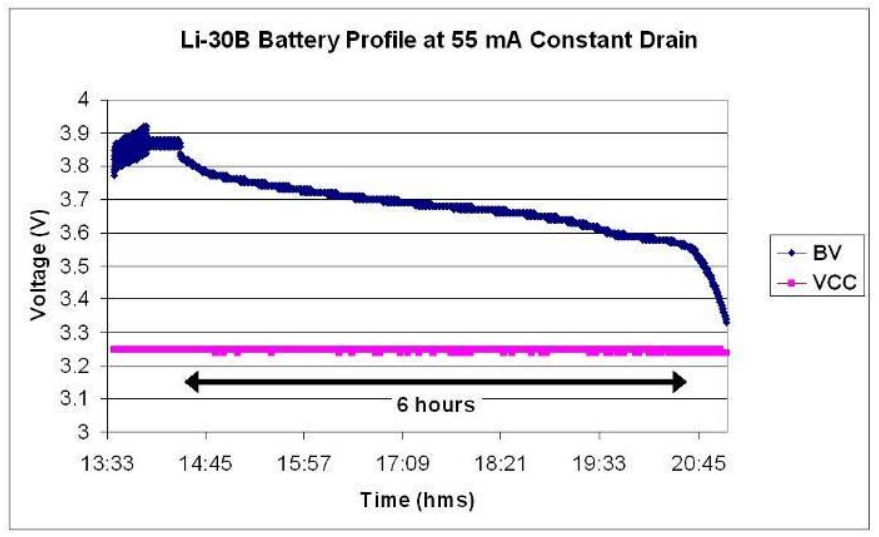

Figure 12. Li-Ion Battery Discharge Test

\subsection{DH and Software Test Results}

Beyond basic functional testing, the DH subsystem testing is mainly focused on the software development. Because the characteristics of many of the hardware components are not known until they are interfaced with the CPU, only skeleton code was able to be written before a completed PCB was available. To enable progression of testing of subsystems, some of the software had to be developed as the overall system was tested. The first revision of the PCB allowed much of the software to be developed. The bulk of the code for the first revision was to support the ATR2406 transceiver, which required significant processor support. In the second revision, much of the ATR2406 software was eliminated as the XBee modules have their own CPU. However, the GPS and CMOS imager required a non-trivial amount of software. The CPU draws $5 \mathrm{~mA}$ while running. There are multiple power saving modes for the CPU, radio, GPS module, and CMOS Imager, which have not been implemented yet which will further reduce the system power.

\subsection{Comm Test Results}

The XBee Pro modules were used because of their higher RF output power. As advertised, they were able to stream data at $115.2 \mathrm{kbps}$. While receiving, they draw $170 \mathrm{~mW}$. While transmitting, which is a very short amount of time, they draw $890 \mathrm{~mW}$. The effective range in an open field is $1.5 \mathrm{~km}$ at the full output power setting of $100 \mathrm{~mW} \mathrm{RF}$.

\subsection{AOCS Test Results}

Testing of the attitude determination and control components was straightforward. Basic functionality of the sun sensors was all that was needed for the attitude determination. For attitude control, the torque rod current draw was measured at $100 \%$ duty cycle and was found to be $10 \mathrm{~mA}$ as designed.
The orbit determination component, which was the GPS module, required surprisingly little testing. Since it was the most significant addition to the second PCB revision, it was mounted and tested first even before the CPU or any other components were mounted. The reason for doing this was to establish a performance baseline before other potentially noisy components were installed.

The first test of the GPS module was a disappointment, as lock could not be achieved. After struggling to find the source of the problem, it was found that poor ground connections from the module to the PCB were the problem, as the module is sensitive to ground noise. After consulting with a soldering technician, the proper soldering technique was learned and applied. This resulted in the module achieving GPS lock from a cold start in 27 seconds, which is near the advertised typical value of 33 seconds. While powered on, the GPS receiver draws $130 \mathrm{~mW}$.

\subsection{Thermal Test Results}

The thermal subsystem was a functional test of the two thermistors. Testing also included calibration of the thermistors to set the telemetry coefficients in software. After calibration, the battery reached a steady state temperature of $25^{\circ} \mathrm{C}$ during constant drain at a room temperature of about 23 ${ }^{\circ} \mathrm{C}$. The solar array hot and cold tests used the results from the solar array thermistor.

\section{CHALLENGES AND FUTURE DIRECTION}

The next phase of the design will focus on a real space mission, discussed in the next section. For PCBSat to operate in the space environment, a number of challenges need to now be addressed. If the project were initiated with spaceflight in mind, then considerations of the space environment would have been incorporated at the start of the design. The complete space systems engineering approach will be use for the next iteration of the design [56]. A short summary of minimum considerations for any mission follows.

The space environment introduces unique problems for systems operating in space that are not normally encountered in a terrestrial environment. Space debris, radiation, vacuum, atmospheric drag in LEO, and the freefall environment are all hazards that require specific design considerations. Additionally, the launch environment must be considered.

Other debris in orbit is not necessarily a threat to PCBSat, but the greatest criticism to date for missions requiring a large number of satellites is becoming debris. The thought is to use PCBSat in missions that are very short-lived, so that the satellites will reenter with a few months after deployment.

Radiation and charged particles, whose fluence varies with altitude, is one of the main problems addressed when flying COTS components in space. Long-term exposure to radiation causes a degradation of performance and increased power draw due to the total ionizing dose effect, which will not be a concern for short-lived missions like PCBSat will support. However, four to eight mils of coverglass for the solar cells and a small amount of aluminum spot shielding on the ICs will be required. Single event upsets will be the main concern. 
The vacuum of space introduces unique thermal control challenges, as the convective heat transfer with the air in terrestrial environment mitigates non-space system thermal problems. The spacecraft structure, in addition to ensuring the satellite survives launch, can be purposely designed to ensure the proper thermal environment. While aluminum is typically used, plastic, such as Delrin ${ }^{\circledR}$, will be considered.

Finally, the orbital environment of freefall introduces more design considerations, for the spacecraft itself and the constellation. The upper atmosphere encountered in LEO, where PCBSat will fly, will impact the system lifetime and differential drag on the nodes in the constellation. The natural spreading out of the nodes must be well understood and traded off against the communication range between nodes. There are some proposed ways to control some orbital parameters using non-propulsive stationkeeping techniques [60].

The set of proposed mission applications in the next section do not require any attitude control, but in general, it is desired to maintain some attitude control. A combination of simple passive and active techniques have been proposed to maintain attitude control where the requirements are not critical [61].

\subsection{MISSION APPLICATIONS}

From an industrial perspective, where commercial applications of small spacecraft are only just appearing, there is a tendency towards growth in spacecraft size, mass, and complexity in order to mitigate risk and meet commercial requirements. Using the distributed space mission approach, where individual spacecraft can be made smaller, spreading the mission's risk across the constellation is attractive. This must be weighed against physical limits, particularly in aperture size. This means that very small spacecraft will struggle to perform some of the near commercial missions such as frequent revisit Earth imaging, which is currently the largest commercial market driver.

However, as discussed in Section 2, there is a family of space weather missions that have yet to be realized without the ability to take simultaneous measurements of phenomena over a large volume. One such mission is the detection and mapping of "plasma bubbles," more accurately known as ionospheric plasma depletions, which cause satellite communication outages when these depletions disrupt or scintillate the signal, as depicted in Figure 13. Such missions will have impact on commercial, government, and military sectors, which all depend on satellite communications for commerce, political stability, and military operations.

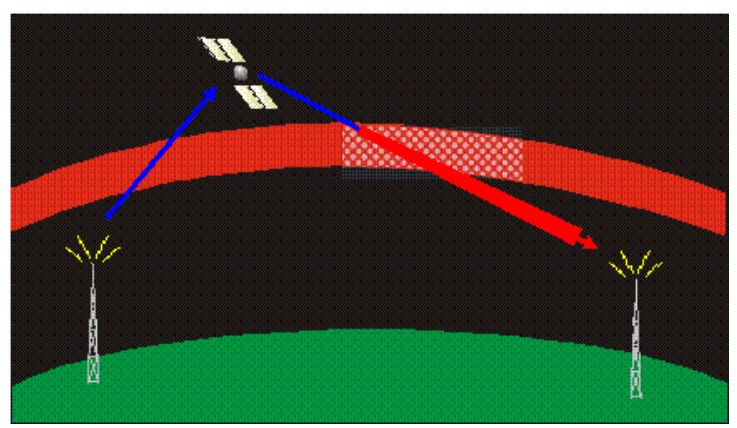

Figure 13. Satellite Communication Signal Scintillation
Another mission that is being considered is detailed mapping of the LEO drag environment. Therefore, the next phase of this project is to develop the space segment and architecture for a dual mission to study plasma depletions and the drag environment. The Miniature Electrostatic Analyzer (MESA) has been identified as a candidate payload for the scintillation study [62]-[64].

MESA was designed, built, and tested in plasma environments created in terrestrial test chambers in 2002. MESA was integrated with FalconSAT-2, which was destroyed during launch in 2005 [65]. Work has progressed since that time to miniaturize the sensor further, making it possible for integration with the PCBSat project, as it has a mass of only a few grams and requires very little power, which would already fit within the PCBSat EPS budget. The data rate requirements are also very low, suitable for the $115.2 \mathrm{kbps}$ wireless communication links. The MESA sensor is shown in Figure 14.

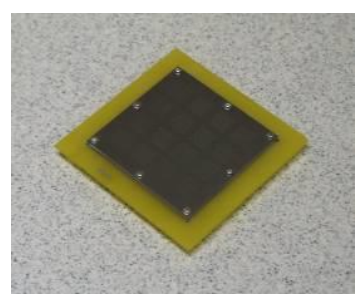

Figure 14. USAF Academy Developed MESA Sensor

For the second mission, an ultra-sensitive accelerometer has been considered as the key payload for the drag environment monitoring [65]. It is not yet certain if the device can be made available for this project.

The mission architecture will also need to be developed, as there are many issues yet to be solved. Similar to the SMAD mission architecture, the U.S. DoD Architecture Framework is being considered for the template [66]. In addition to the space environment considerations, the natural spreading out of the nodes must be well understood and traded off against the inter-satellite commutation range and the locality of the supporting data relay satellite(s). The possibility of using existing commercial LEO satellite for data relay will be considered as well.

The final system configuration is envisioned to be a $10 \times 10 \times 2$ $\mathrm{cm}$ block as shown in Figure 15. It would be designed to be compatible with the existing PPOD launcher, where 15 PCBSats could be jettisoned from each PPOD [34].

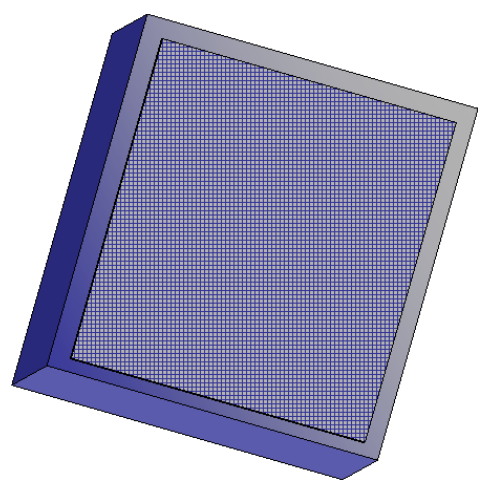

Figure 15. Conceptual Final Design of PCBSat 


\subsection{SPIN-OFF APPLICATIONS}

The possibility of spin-off applications was identified early in the project. Due to the author's continued support of the EyasSAT Educational Satellite System project managed by the USAF Academy, it was realized that by accepting certain design constraints, that this project could benefit EyasSAT in two tangible ways. The most important spin-off was the ability to offer a payload module option for EyasSAT, which currently does not exist. As described in Section 4, current revision of PCBSat has successfully been used as an EyasSAT payload, adding a GPS receiver and CMOS Imager to the system.

The EyasSAT project has always had a goal of encouraging student built payloads and subsystems to be created by the user community. Since no one else has yet stepped up to the challenge, publicizing this development will hopefully encourage students at other universities to build one. The University of Surrey has already integrated EyasSAT into several of its courses and is currently investigating the possibility of integrating student-built payloads and subsystems for EyasSAT into their space-related undergraduate and graduate programs [55].

Another spin-off application with much less widespread impact are the lessons learned in the latest COTS components, improved EPS designs, and GPS technologies. These lessons can be applied to the next EyasSAT design, which is currently in progress.

\section{CONCLUSIONS}

A new class of distributed space missions is emerging which requires large numbers, perhaps hundreds to thousands, of satellites to achieve long-awaited remote sensing and science mission objectives. These missions can be enabled with a low-cost mass-producible solution by merging the concepts of distributed space systems and terrestrial wireless sensor networks. However, unlike terrestrial wireless sensor nodes, distributed space system nodes must be designed to survive the space environment while in orbit. A novel sub-kilogram very small satellite design is required.

This paper was presented with a problem-solution approach. The problem or challenge in this case, is the fact that numerous envisioned distributed space missions with great benefit to society are waiting for technical solutions to be developed. Most of the academic excitement currently surrounds a few missions that require small clusters of formation flying satellites, each being very complex. The problems yet to be solved associated with formation flying are numerous and each very challenging. In contrast, there are numerous beneficial missions, such as space weather, that rely on less complex architectures based on traditional satellite constellations to achieve real-time, distributed, multi-point sensing. However, these architectures require hundreds to thousands of low-cost, mass-producible satellite nodes.

An initial prototype of a femtosatellite has been designed, built, and tested successfully using commonly available commercial parts and practices at a unit cost of $\$ 300$. The first two designs of PCBSat are clearly focused on function and performance. The next step is to focus on the selected ionospheric plasma depletion mission to enhance our understanding of scintillation on communication links through the atmosphere. Meeting mission requirements, solving the space environment problems, and developing a mission architecture are the challenges that lie ahead. It is estimated that the per node cost will not exceed $\$ 1000$ and the system will able to be deployed en masse with existing launch vehicle interfaces. A summary of the current system configuration is shown in Table 7 below.

Table 7. PCBSat Current System Configuration

\begin{tabular}{|c|c|}
\hline System mass & $70 \mathrm{~g}$ \\
\hline Dimensions & $9.0 \times 9.5 \times 1 \mathrm{~cm}(\mathrm{PC} 104)$ \\
\hline Cost & $\$ 300$ per prototype \\
\hline Payload & - 640x480 CMOS Imager \\
\hline Electrical Power Subsystem & $\begin{array}{l}\text { - 3.3V regulated system bus } \\
\text { - } 689 \mathrm{~mW} \text { silicon solar array } \\
\text { - } 645 \mathrm{mAh} \text { Li-Ion battery } \\
\text { - Peak power tracking } \\
\text { - Battery charge regulation } \\
\text { - 6-channel telemetry }\end{array}$ \\
\hline Data Handling Subsystem & $\begin{array}{l}\text { - Mega128L microcontroller } \\
\text { - } 3.6864 \mathrm{MHz} \text { system clock } \\
\text { - Real time clock w/backup }\end{array}$ \\
\hline Communications Subsystem & $\begin{array}{l}\text { - 2.4 GHz, } 60 \mathrm{~mW} \text { RF } \\
\text { - ZigBee protocol } \\
\text { - } 115.2 \mathrm{kbps} \text { data rate } \\
\text { - } 1.3 \mathrm{~km} \text { terrestrial range } \\
\text { - Signal strength telemetry }\end{array}$ \\
\hline $\begin{array}{l}\text { Attitude and Orbit Control } \\
\text { Subsystem }\end{array}$ & $\begin{array}{l}\text { - Passive aerodynamic } \\
\text { - Active single magnetorquer } \\
\text { - Two sun sensors } \\
\text { - GPS receiver }\end{array}$ \\
\hline Thermal Control Subsystem & $\begin{array}{r}\text { - Solar cell and battery } \\
\text { temperature monitors }\end{array}$ \\
\hline Structural Subsystem & - TBD \\
\hline Propulsion & - None planned \\
\hline
\end{tabular}

\section{ACKNOWLEDGEMENTS}

The views expressed in this article are those of the author and do not reflect the official policy or position of the United States Air Force, Department of Defense, or the U.S. Government. Cleared for public release, distribution unlimited by the U.S. Air Force Institute of Technology Public Affairs \#060923. This material is declared a work of the United States Government and is not subject to copyright protection in the United States. 


\section{REFERENCES}

[1] K. Romer and F. Mattern, "The Design Space of Wireless Sensor Networks," IEEE Wireless Communications, vol. 11, no. 6, December 2004, pp. 54-61.

[2] D. J. Barnhart, T. Vladimirova, and M. N. Sweeting, "Satelliteon-a-Chip: A Feasibility Study," in Proc. 5th Round Table on Micro/Nano Technologies for Space, Nordwijk, 2005.

[3] D. J. Barnhart, T. Vladimirova, and M. N. Sweeting, "Satelliteon-a-Chip Development for Future Distributed Space Missions," in Proc. CANEUS Conference on Micro-Nano Technologies for Aerospace Applications, Toulouse, France, 2006, Paper CANEUS2006-11045.

[4] C. D. Jilla and D. W. Miller, "Multi-Objective, Multidisciplinary Design Optimization Methodology for Distributed Satellite Systems," Journal of Spacecraft and Rockets, vol. 41, no. 1, January-February 2004, pp. 39-50.

[5] R. Burns, C. Cheung, G. Davis, E. Cary, J. Higinbotham, and K. Hogie, "A System for Real-Time, Closed-Loop, MultiSpacecraft Mission Simulation Applications," in Proc. AIAA Modeling and Simulation Technologies Conference and Exhibit, Austin, TX, 2003, Paper AIAA-2003-5381.

[6] G. B. Shaw, D. W. Miller, and D. E. Hastings, "Generalized Characteristics of Communication, Sensing, and Navigation Satellite Systems," Journal of Spacecraft and Rockets, vol. 37 , no. 6, November-December 2000, pp. 801-811.

[7] T. P. Garrison, M. Ince, J. Pizzicaroli, and P. A. Swan, "Systems Engineering Trades for the IRIDIUM® Constellation," Journal of Spacecraft and Rockets, vol. 34, no. 5, September-October 1997, pp. 675-680.

[8] R. Peters, "Commercial Inter-Satellite Links, What Happened?" in Proc. 21st International Communications Satellite Systems Conference and Exhibit, Yokohama, Japan, 2003, Paper AIAA2003-2325.

[9] A. da Silva Curiel, "Small Satellite Constellations for Earth Observation," in Proc. 55th International Astronautical Congress, Vancouver, Canada, 2004, Paper IAC-04-11.4.08.

[10] D. Sieg, "Optimization of New 4 S/C Formations Considering Operational Constraints of the Extended Cluster Mission," in Proc. $18^{\text {th }}$ International Symposium of Space Flight Dynamics, Munich, Germany, 2004.

[11] F. Serene and N. Corcoral, "PARASOL and CALIPSO: Experience Feedback on Operations of Micro and Small Satellites," in Proc. SpaceOps 2006 Conference, Rome, 2006, Paper AIAA-2006-5919.

[12] J. Ray, "Tiny Probes Launched to Test Advanced Technologies," Spaceflight Now, March 22, 2006 [Online]. Available: http://www.spaceflightnow.com/pegasus/st5/

[13] C. Fong, B. Wu, N. Yen, and P. Chen, "Application of FORMOSAT-3/COSMIC Mission to Global Earth Monitoring," in Proc. AIAA Space 2005, Long Beach, CA, 2005, Paper AIAA-2005-6774.

[14] E. Ashford, "Non-Geo Systems...where have all the Satellites Gone?" in Proc. 54th International Astronautical Congress, Bremen, 2003, Paper IAC-03-M.4.01.

[15] S. Norris, "Commercial Applications for Microsatellites," in Proc. AIAA Space 2001, Albuquerque, NM, 2001, Paper AIAA2001-4743.

[16] C. Edery-Guirardo, J. P. Aguttes, E. Bouisson, and F. Forestier, "Small Relay Satellites for Improving the Reactivity of Observation Satellites," in Proc. 54th International Astronautical Congress, Bremen, 2003, Paper IAC-03-B.2.04.

[17] E. Lagier and D. Craig, "JAMFEST - A Cost Effective Solution to GPS Vulnerability Testing," in Proc. USAF Developmental Test and Evaluation Summit, Woodland Hills, CA, 2004, Paper AIAA-2004-6853.
[18] M. Bille, R. Kane, and M. Nowlin, "Military Microsatellites Matching Requirements and Technology," in Proc. AIAA Space 2000, Long Beach, CA, 2000, Paper AIAA-2000-5186.

[19] M. N. Sweeting, "Shaping the Future," University of Surrey Annual Report 2004/2005, p. 5, [Online]. Available: http://portal.surrey.ac.uk/pls/portal/docs/PAGE/GATEWAY/CO RPORATE/ANNUAL\%20REPORT\%20UNIVERSITY\%20OF \%20SURREY_0.PDF

[20] A. Das, R. Cobb, and M. Stallard, "Techsat 21 - A Revolutionary Concept in Distributed Space-based Sensing," in Proc. AIAA Defense and Civil Space Programs Conference and Exposition, Huntsville, AL, 1998, Paper AIAA-1998-5255.

[21] J. G. Macke, D. P. Miller, M. A. Swartwout, K. J. Bennett, and W. D. Smart, "Deployable Inspector Spacecraft for Distributed Field Measurements," in Proc. 22nd AIAA International Communications Satellite Systems Conference and Exhibit, Monterey, CA, 2004, Paper AIAA-2004-3152.

[22] F. A. Herrero, M. DiJoseph, T. E. Moore, J. A. Slavin, and R. Vondrak, "NanoSat Constellations for Geospace Science," in Proc. AIAA Space 2000, Long Beach, CA, Paper AIAA-20005174.

[23] W. T. Huntress, "Statement of NASA to Congress," Subcommittee on Space and Aeronautics, Committee on Science, U.S. House of Representatives, April 1997.

[24] L. H. Krause, C. L. Enloe, R. K. Haaland, and P. Golando, "Microsatellite Missions to Conduct Midlatitude Studies of Equatorial Ionospheric Plasma Bubbles," Advances in Space Research, vol. 36, no. 12, 2005, pp. 2474-2479.

[25] G. Blackwood, C. Henry, E. Serabyn, S. Dubovitsky, M. Aung, and S. Gunter, "Scope and Objectives of the Terrestrial Planet Finder Interferometer Study," in Proc. AIAA Space 2003, Long Beach, CA, 2003, Paper AIAA-2003-6329.

[26] P. Ferguson, F. Busse, B. Engberg, J. How, M. Tillerson, N. Pohlman, A. Richards, and R. Twiggs, "Formation Flying Experiments on the Orion-Emerald Mission," in Proc. AIAA Space 2001, Albuquerque, NM, 2001, Paper AIAA-2001-4688.

[27] J. Carpenter, J. Leitner, D. Folta, and R. Burns, "Benchmark Problems for Spacecraft Formation Flying Missions ," in Proc. AIAA Guidance, Navigation, and Control Conference and Exhibit, Austin, TX, 2003, Paper AIAA-2003-5364.

[28] Surrey Satellite Technology Limited, "Small Satellites Home Page," [Online]. Available: http://centaur.sstl.co.uk/SSHP/index.html

[29] C. I. Underwood, G. Richardson, and J. Savignol, "SNAP-1: A Low Cost Modular COTS-Based Nano-Satellite - Design, Construction, Launch and Early Operations Phase," in Proc. 15th Annual AIAA/USU Conference on Small Satellites, Logan, UT, 2001, Paper SSC01-V-1a.

[30] F. Bruhn, J. Köhler, and L. Stenmark, "NanoSpace-1: the Impacts of the First Swedish Nanosatellite on Spacecraft Architecture and Design," in Proc. 53rd International Astronautical Congress, Houston, TX, 2002, Paper IAC-02U.4.01.

[31] F. Bruhn and L. Stenmark, "NanoSpace-1: Spacecraft Architecture and Design after Concluding Phase B," in Proc. 5th Round Table on Micro/Nano Technologies for Space, Nordwijk, 2005.

[32] M. Hapgood, S. Eckersley, R. Lundin, M. Kluge, U. Prechtel, and P. Hyvönen, "Nano Satellite Beacons for Space Weather Monitoring," in Proc. 5th Round Table on Micro/Nano Technologies for Space, Nordwijk, 2005.

[33] V. Srinivasan, "Students Launch OPAL Satellites," The Stanford Daily, 17 February 2000 [Online]. Available: http://www.stanforddaily.com/tempo?page $=$ content $\& \mathrm{id}=2171 \& \mathrm{r}$ epository=0001_article 
[34] I. Nason, J. Puig-Suari, and R. Twiggs, "Development of a Family of Picosatellite Deployers Based on the CubeSat Standard," in Proc. 2002 IEEE Aerospace Conference, Big Sky, MT, vol. 1, 2000, pp. 1-457 - 1-464.

[35] Clyde Space Ltd., "CubeSat Power: A Power System for Miniature Spacecraft," [Online]. Available: http://www.clydespace.com/Cubesat_Power.html

[36] C. I. Underwood, V. J. Lappas, A. da Silva Curiel, M. Unwin, A. M. Baker, and M. N. Sweeting, "Using PALMSAT PicoSatellite Technologies to Meet Mission Scenarios," in Proc. 55th International Astronautical Congress, Vancouver, Canada, 2004, Paper IAC-04-P.5.A.01.

[37] H. Helvajian and S. W. Janson, "The Fabrication of a $100 \mathrm{gm}$ Co-Orbiting Satellite Assistant (COSA) Using Glass Ceramic Materials And 3-D Laser Processing Techniques," in Proc. 9th International Micromachine/Nanotech Symposium, Tokyo, Japan, 2003, pp. 33-41.

[38] Cyrospace, Inc., "Femtosatellite is the smallest operational satellite ever built," [Online]. Available: http://www.cyrospace.com/products/pdfs/CyroBro_SS.pdf

[39] S. W. Janson, H. Helvajian, S. Amimoto, G. Smit, D. Mayer, and S. Feuerstein, "Microtechnology for Space Systems," in Proc. 1998 IEEE Aerospace Conference, Big Sky, MT, vol. 1, 1998, pp. 409-418.

[40] H. Helvajian, Microengineering Aerospace Systems, Reston, VA, AIAA Press, 1999.

[41] S. W. Janson, H. Helvajian, and K. Breuer "MEMS, Microengineering and Aerospace Systems," in Proc. 30th AIAA Fluid Dynamics Conference, Norfolk, VA, 1999, Paper AIAA1999-3802.

[42] S. W. Janson, "Mass-Producible Silicon Spacecraft for 21st Century Missions," in Proc. AIAA Space 1999, Albuquerque, NM, 1999, Paper AIAA-1999-4458.

[43] S. W. Janson, "Nanotechnology - Tools for the Satellite World," Keynote Address, 6th ISU Annual International Symposium; "Smaller Satellites, Bigger Business?", Strasbourg, France, 2001, pp. 21-30.

[44] S. W. Janson, "Micro/Nanotechnology for Micro/Nano/Picosatellites," in Proc. AIAA Space 2003, Long Beach, CA, 2003, Paper AIAA-2003-6269.

[45] S. Janson, A. Huang, W. Hansen, L. Steffeney, and H. Helvajian, "Development of an Inspector Satellite Using Photostructurable Glass/Ceramic Materials," in Proc. AIAA Space 2005, Long Beach, CA, 2005, Paper AIAA-2005-6802.

[46] L. Xuwen, L. Li, L. Huawang, C. Yinjian, S. Dexin, and Y. Genqing, "Silicon Solid-state Small Satellite Design Based on IC and MEMS," in Proc. 1998 5th International Conference on Solid-State and Integrated Circuit Technology, Beijing, 1998, pp. 932-935.

[47] R. J. Shul, S. H. Kravitz, T. R. Christenson, C. G. Willison, T. E. Zipperian, "Silicon Microfabrication Technologies for Nanosatellite Applications," in Proc. ASCE Space 2000: The Seventh International Conference and Exposition on Engineering, Construction, Operations, and Business in Space, Albuquerque, NM, 2000, pp. 482-487.

[48] B. Jackson and K. Epstein, "A Reconfigurable Multifunctional Architecture Approach for Next-Generation Nanosatellite Design," in Proc. 2000 IEEE Aerospace Conference, Big Sky, MT, vol. 7, 2000, pp. 185-193.

[49] K. Miller, C. Mogensen, and T. Gillespie, "Innovative, Low Cost Microspacecraft," in Proc. AIAA Space 2000, Long Beach, CA, 2000, Paper AIAA-2000-5196.

[50] T. Mosher and B. Stucker, "Responsive Space Requires Responsive Manufacturing-Part II," in Proc. AIAA Space 2004, San Diego, CA, 2004, Paper AIAA-2004-6117.
[51] M. Pimprikar and T. George, "CANEUS NPS (Nano-PicoSatellites) Inc. to Develop the World's Most Advanced Miniature Satellites," [Online]. Available: http://www.caneus.org/CANEUS06/CANEUS_NPS.ppt

[52] J. Keller interview of A. Joshi, "Startup to Develop Satellite-OnA-Chip," Military \& Aerospace Electronics, February 1994 [Online]. Available: http://www.chipsat.com/press/press01.php

[53] D. J. Barnhart, O. NG Ritchey, J. J. Sellers, J. J. White, T. L. White, and J. B. Clark, "EyasSAT: Transforming the Way Students Experience Space Systems Engineering," in Proc. 2004 ASEE Annual Conference \& Exposition Proceedings, Salt Lake City, UT, 2004.

[54] D. J. Barnhart, J. J. Sellers, C. A. Bishop, J. R. Gossner, J. J. White, and J. B. Clark, "EyasSAT: A Revolution in Teaching and Learning Space Systems Engineering," in Proc. AIAA Space Systems Engineering Conference, Atlanta, GA, November 2005.

[55] D. J. Barnhart, T. Vladimirova, A. Ellery, V. J. Lappas, C. I. Underwood, and M. N. Sweeting, "Utilising the EyasSAT Concept in Space Systems Engineering Courses at the University of Surrey," in Proc. International Astronautics Congress, Valencia, Spain, 2006, Paper IAC-06-E1.4.04.

[56] J. R. Wertz and W. J. Larson, Space Mission Analysis and Design, 3rd Edition, El Segundo, CA, Microcosm Press, 1999.

[57] T. P. Sarafin, Spacecraft Structures and Mechanisms, El Segundo, CA and The Netherlands, Microcosm and Kluwer Publishing, 1995.

[58] Maxim Integrated Products, "Harnessing Solar Power with Smart Power-Conversion Techniques," Application Note 484, [Online]. Available: http://www.maxim-ic.com/appnotes.cfm/appnote_number/484

[59] M. J. Unwin and M. K. Oldfield, "The Design and Operation of a COTS Space GPS Receiver," Guidance and Control, vol. 104, 2000, Paper AAS00-046.

[60] T. Williams and Z-S. Wang, "Potential Non-propulsive Stationkeeping Techniques for Picosatellite Formation Flight," in Proc. AIAA/AAS Astrodynamics Specialist Conference, Denver, CO, 2000, AIAA-2000-4134.

[61] M. L. Psiaki, "Nanosatellite Attitude Stabilization Using Passive Aerodynamics and Active Magnetic Torquing," Journal of Guidance, Control, and Dynamics, vol. 27, no. 3, May 2004, pp. 347-355.

[62] C. L. Enloe, L. H. Krause, and R. K. Haaland, "Miniaturized Electrostatic Analyzer Manufactured Using Photolithographic Etching," Review of Scientific Instruments, vol. 74, no. 3, 2003, pp. 1192-1195.

[63] L. H. Krause, C. L. Enloe, R. K. Haaland, and P. Golando, "Microsatellite Missions to Conduct Midlatitude Studies of Equatorial Ionospheric Plasma Bubbles," Advances in Space Research, vol. 36, no. 12, 2005, pp. 2474-2479.

[64] L. H. Krause, C. L. Enloe, and R. K. Haaland, "Fast In-Situ Measurements of Ionospheric Plasma with the Miniature Electrostatic Analyzer (MESA): An Experiment Aboard FalconSAT-2," in Proc. 2002 IEEE Aerospace Conference Proceedings, vol. 2, 2002, pp. 2-631 - 2-639.

[65] F. T. Hartley, "Development and Terrestrial Applications of a Nano-g Accelerometer," Proceedings of the SPIE-Electronics and Structures for MEMS, vol. 3891, September 1999, pp. 410415.

[66] DoD Architecture Framework Working Group, "DoD Architecture Framework Version 1.0,” vol. 1, 9 February 2004. Available: http://www.defenselink.mil/nii/doc/DoDAF_v1_Volume_I.pdf 